NIST Economic Analysis Briefs 3

\title{
The Economic Impact of Technology Infrastructure for Additive Manufacturing
}

\author{
Gary Anderson (gary.anderson@nist.gov) \\ Technology Partnerships Office, Innovation \& Industry Services
}

\section{Key Findings}

October 2016

- Conservative estimates indicate that meeting the identified technology infrastructure needs would save additive manufacturers $\$ 4.1$ billion annually. Benefits attributable to enhanced product quality, market growth and R\&D costs savings which are identified but not quantified would greatly increase this estimate.

- Barriers to innovation increase the cost of additive manufacturing $R \& D$, weaken private investment incentives and foster proprietary standards that can distort the market.

- Closing select technical gaps while leaving other needs unmet would significantly limit the benefits to domestic manufacturers.

- Small firms are particularly disadvantaged by current gaps in the technology infrastructure.

\section{Introduction}

Across an array of industries from aerospace to personalized medical devices, additive manufacturing (AM) technologies are used to make objects and parts by joining ultrathin layers of material layer by layer. A recent study ${ }^{1}$ commissioned by the National Institute of Standards and Technology (NIST) finds AM has great "potential to enable both sustaining and disruptive innovation but is held back by inadequate technology infrastructure needed to support the further development and application of AM technologies." Technology infrastructure ${ }^{2}$ is the broad base of public and quasi-public technologies and technical knowledge that support the research, development, production and diffusion activities of national laboratories, universities and firms alike. The unique contribution of this study is to identify AM technology needs closely aligned with NIST's mission and estimate the impact of meeting these needs.

After conducting nearly 60 in-depth interviews with researchers, developers, manufactures and other stakeholders involved with additive manufacturing, the study identified technology infrastructure needs - "currently unmet needs for measurement science, including metrology and test methods, traceable reference data, and other formal knowledge-that limit AM technology's further development and adoption, and the ways in which meeting these needs could spur innovation and growth in US advanced manufacturing." Meeting such needs is part of the NIST mission to promote U.S. innovation and industrial competitiveness. The study conservatively estimates that meeting these needs would save U.S. manufactures $\$ 4.1$ billion annually representing an $18.3 \%$ reduction in the cost of goods sold. This estimate only includes manufacturing cost savings attributable to factors such as reduced time and cost to test and validate materials, reduced and cost to reach first successful build, and a lowered scrap rate. The estimate does not include harder to measure impacts such as research cost savings, the benefits of new improved performance 
Table 1: Technology Infrastructure Gaps and Potential Benefits

\begin{tabular}{|c|c|}
\hline $\begin{array}{l}\text { Industry Technology Infrastructure } \\
\text { Needs }\end{array}$ & Examples of Economic Impacts \\
\hline $\begin{array}{l}\text { Standards-standards, best practices, } \\
\text { and reference data for materials and } \\
\text { AM processes }\end{array}$ & $\begin{array}{l}\text { - Improve confidence via reproducibility across } \\
\text { manufacturing methods } \\
\text { - Provide greater assurance in raw materials }\end{array}$ \\
\hline $\begin{array}{l}\text { Metrology-real-time, in situ } \\
\text { metrology, enabled by integrated } \\
\text { sensors for real-time feedback during a } \\
\text { build }\end{array}$ & $\begin{array}{l}\text { Identify in-build defects in time to correct and } \\
\text { continue the build or scrap before using additional } \\
\text { material }\end{array}$ \\
\hline $\begin{array}{l}\text { Design Allowables-design } \\
\text { optimization tools and protocols for } \\
\text { complex builds }\end{array}$ & $\begin{array}{l}\text { - Improve "design to manufacture" guidance for } \\
\text { designing and printing complex parts, including } \\
\text { mesh, lightweight, and sacrificial support structures } \\
\text { - Reduce scrap rates and turnaround times and } \\
\text { improve reliability and reproducibility of parts }\end{array}$ \\
\hline $\begin{array}{l}\text { Modeling and Simulation-high-fidelity } \\
\text { process modeling and simulation for } \\
\text { different materials and designs }\end{array}$ & $\begin{array}{l}\text { - Improve yields, shorter and fewer R\&D cycles } \\
\text { - Predict anomalies at various stages of a build } \\
\text { - Understand material-specific processes leading to } \\
\text { new applications }\end{array}$ \\
\hline $\begin{array}{l}\text { Surface Finishing-cost-effective } \\
\text { approaches to improve surface finishing } \\
\text { of metal AM parts and standards for } \\
\text { measuring surface finish and tolerances }\end{array}$ & $\begin{array}{l}\text { - Eliminate or greatly reduce the degree of } \\
\text { postprocessing required to make production-quality } \\
\text { parts }\end{array}$ \\
\hline $\begin{array}{l}\text { Testing Procedures-innovative } \\
\text { mechanical testing procedures }\end{array}$ & $\begin{array}{l}\text { - Improve efficiency and cost savings from } \\
\text { nondestructive and other test methods } \\
\text { - Improve confidence in AM processes and materials } \\
\text { to speed up adoption and validation of high-value } \\
\text { printed parts in various applications }\end{array}$ \\
\hline
\end{tabular}

characteristics enabled by AM, the emergence of new products and markets, or a range of additional societal benefits.

Through these in-depth interviews the analysis first identified six broad areas of technical need and then identified the qualitative benefits of meeting these needs and estimated manufacturing cost savings of providing industry with the new technical capabilities. The identified needs and quantitative benefits of meeting those needs are summarize in Table 1 and Figure 1, respectively.

The needs include verified reference data, robust measurements technologies, and testing methods as well as design, modeling and finishing technologies. The analysis draws on interviews from stakeholders throughout entire supply chains including AM materials developers, AM equipment manufacturers, industry associations, standards organizations as well as end users of AM technology across a variety of manufacturing sectors including aerospace, automotive, consumer products, biomedical device, and dental implant manufacturing sectors. 
Figure 1: Total Annual Impact, Apportioned by Technology Need (Millions of 2013 US\$)

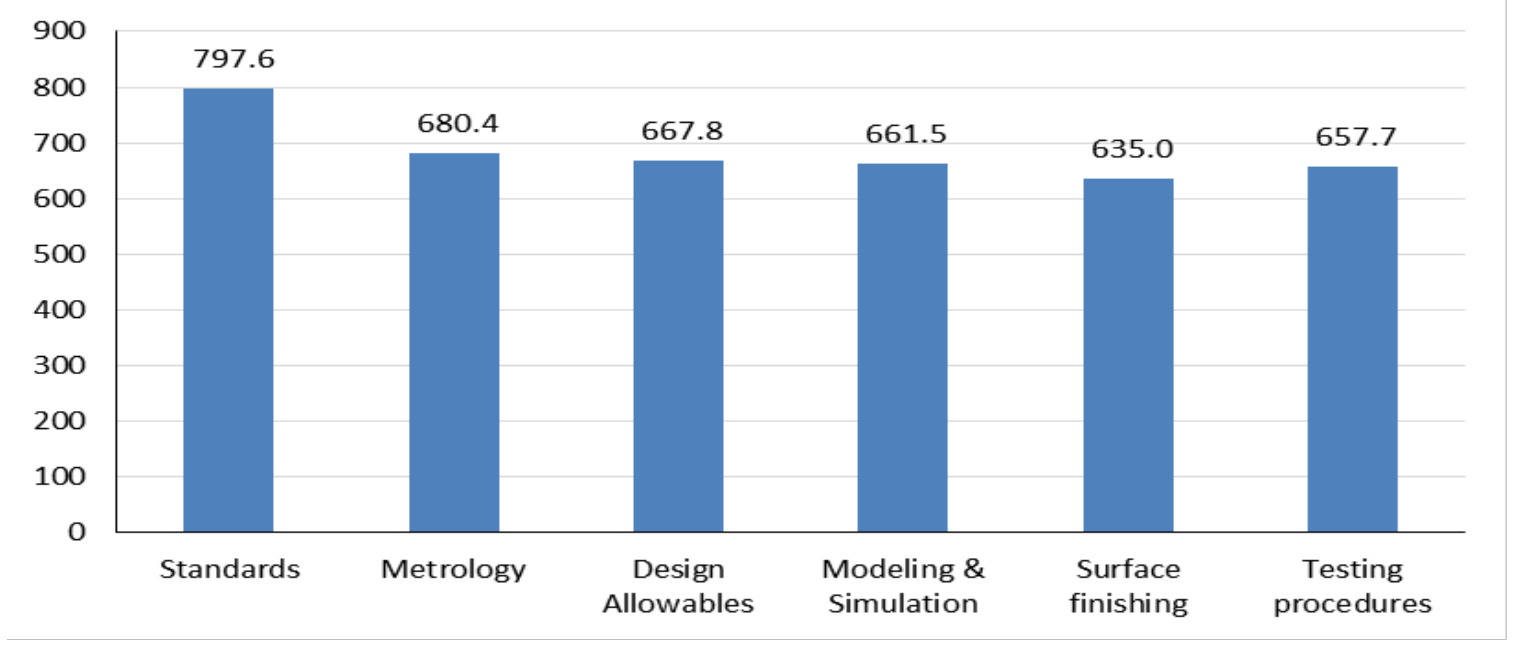

\section{Key Findings}

First, the analysis indicates that the benefits to meeting the identified technology infrastructure needs are large. The study identifies $\$ 4.1$ billion in annual cost savings to end-use manufacturing companies should the identified scientific and technical needs be met. This number is particularly impressive since it does not include benefits that interviewees could not rigorously quantify such as R\&D cost savings, transactions cost savings, benefits of new and improved products, long-term growth and competitiveness benefits of AM, or other societal benefits.

The study also identifies distinct barriers to innovation, caused by market failures ${ }^{3}$, beyond the public good nature of technology infrastructure. These barriers create further inefficiencies and magnify the role of public institutions in meeting these scientific and technical needs. The infrastructure gaps alongside critical uncertainties and network effects ensure that current AM research, development and deployment is excessively costly and accessible to a limited set of companies. The stakeholder interviews identify critical uncertainties that increase transactions and adoption costs and diminish the incentive of all parties - across entire supply chains - to invest in AM technology. For example, the analysis finds that end users are often unable to verify AM part quality and performance or even identify whether the potential issues with AM part performance and reliability are caused by underlying issues with AM manufacturing processes, AM equipment, or even the powders and other raw materials. Just as an end user cannot verify the quality of raw materials such as powders, they also cannot verify the quality of proprietary data and testing developed by powder manufacturers. The interviews provide evidence that proprietary standards create market distortions by conveying market power through branding and reputation. Further, the interviews provide evidence that companies may use the standards development process to capture market power. AM end users noted that "gaps in [voluntary consensus] standards may tend to favor the interests of AM systems manufacturers." The end result is that AM research, development and deployment is excessively costly, private investment incentives are weakened and privately developed standards may be further distorting the market.

A third key finding is that there are important linkages among technology infrastructure elements. This increases the importance of ensuring needs are met across all categories. For example, highfidelity computer modeling and simulation require advances in measurement science to populate 
new scientific and engineering databases. Consequently, "unbalanced" investment - closing select technical gaps while leaving other needs unmet - "would likely fail to fully realize economic impact" in the domestic advanced manufacturing sector.

Finally, the analysis indicates that small firms are particularly disadvantaged by current gaps in AM technology infrastructure. Small manufacturers noted that "they do not have the adequate resources to exhaustively test and validate part properties after fabrication and, thus, are prohibited from entering the transportation markets." Similarly, small AM materials supplier reported that the development cycles for new materials were too long to realize a return on investment. In this environment, "property data for a set of common process-material pairs could accelerate the introduction of additively built parts into service in existing industries, as well as new industries, and open up additional opportunities for small suppliers and manufacturers."

\section{References}

[1] Anderson G (2013) The Impact of Federally Performed R\&D: Twenty Years of Economic Analysis at the National Institute of Standards and Technology. 2013 Technology Transfer Society Conference.

[2] Link A Scott J (2011) The theory and practice of public-sector R\&D economic impact analysis. (NIST, Gaithersburg, MD) Planning Report 11-1. https://www.nist.gov/sites/default/files/documents/director/planning/report11-1.pdf.

[3] Scott, TJ, Beaulieu TJ, Rothrock GD, O'Connor AC (2016). Economic Analysis of Technology Infrastructure Needs for Advanced Manufacturing: Additive Manufacturing. (NIST, Gaithersburg, MD) NIST GCR 16-006.

[4] Tassey G (2007) The Technology Imperative. (Edward Elgar, Cheltenham).

\footnotetext{
${ }^{1}$ See Scott et al. [3].

${ }^{2}$ Technology infrastructure includes infratechnologies and technology platforms. Infratechnologies are technical tools, such as measurement and test methods, reference materials, scientific and engineering databases, process models, and the technical basis for physical and functional interfaces between individual components of both cyber and physical systems technologies. Technology platforms are precompetitive proofs of concept that demonstrate the potential commercial viability of multiple new or improved products, processes, or services. Technology infrastructure shares many common feature with tangible infrastructure. Namely, it is difficult and even undesirable to exclude potential users implementing the technology and usage of the technology infrastructure by a particular organization does not does not preclude others from benefiting to much the same extent. See Anderson (2013), Link and Scott (2010) and Tassey (2007) for a richer discussion of the public good nature of technology infrastructure.

${ }^{3} \mathrm{~A}$ market failure is a situation where free markets do not allocate resources efficiently. In particular, the study finds evidence that network externalities, high technical risk, uncertainty and asymmetric information, and economies of scope all impact research in additive manufacturing technology infrastructure. The result is that markets invest too few resources in R\&D.
} 